\title{
Plasmid Vectors for Xylella fastidiosa Utilizing a Toxin-Antitoxin System for Stability in the Absence of Antibiotic Selection
}

\author{
Lindsey P. Burbank and Drake C. Stenger
}

United States Department of Agriculture-Agricultural Research Service, San Joaquin Valley Agricultural Sciences Center, 9611 South Riverbend Ave., Parlier, CA 93648-9757.

Accepted for publication 14 April 2016.

\begin{abstract}
Burbank, L. P., and Stenger, D. C. 2016. Plasmid vectors for Xylella fastidiosa utilizing a toxin-antitoxin system for stability in the absence of antibiotic selection. Phytopathology 106:928-936.

The phytopathogen Xylella fastidiosa causes disease in a variety of important crop and landscape plants. Functional genetic studies have led to a broader understanding of virulence mechanisms used by this pathogen in the grapevine host. Plasmid shuttle vectors are important tools in studies of bacterial genetics but there are only a limited number of plasmid vectors available that replicate in $X$. fastidiosa, and even fewer that are retained without antibiotic selection. Two plasmids are described here that show stable replication in $X$. fastidiosa and are effective for gene complementation

both in vitro and in planta. Plasmid maintenance is facilitated by incorporation of the PemI/PemK plasmid addiction system, consisting of PemK, an endoribonuclease toxin, and its cognate antitoxin, PemI. Vector pXf20pemIK utilizes a native $X$. fastidiosa replication origin as well as a high-copy-number pUC origin for propagation in Escherichia coli cloning strains. Broad-host-range vector pBBR5pemIK is a medium- to low-copy-number plasmid based on the pBBR1 backbone. Both plasmids are maintained for extended periods of time in the absence of antibiotic selection, as well as up to 14 weeks in grapevine, without affecting bacterial fitness. These plasmids present an alternative to traditional complementation and expression vectors which rely on antibiotic selection for plasmid retention.
\end{abstract}

Xylella fastidiosa is the causal agent of Pierce's disease of grapevine, citrus variegated chlorosis, and leaf scorch diseases in almond, oleander, and a number of other cultivated plant species (Hopkins 1989; Hopkins and Purcell 2002; Purcell et al. 1999). X. fastidiosa is a fastidious organism limited to growth in specific niches, mainly xylem vessels of the host plant and foregut of the insect vector. A slow rate of replication under laboratory conditions and an extended timeframe for in planta virulence trials make genetic studies of pathogenesis and transmission challenging.

Genetic determinants of virulence in X. fastidiosa have been identified through random or site-directed mutagenesis and confirmed by complementation analysis (Clifford et al. 2013, Guilhabert and Kirkpatrick 2005; Guilhabert et al. 2001; Reddy et al. 2007). An effective complementation strategy using insertion of a gene of interest into a neutral region of the chromosome has been widely used in grape-pathogenic X. fastidiosa strains (Matsumoto et al. 2009). This method relies on homologous recombination between a suicide vector and the bacterial chromosome, limiting use to strains with high sequence similarity. An alternative is to express the gene of interest on a plasmid. However, most commonly used cloning and expression vectors are unable to replicate in $X$. fastidiosa. Plasmid-based complementation methods also rely on stability of the plasmid vector, which varies depending on experimental conditions, selective pressure, and genes expressed (Guilhabert and Kirkpatrick 2003; Matsumoto et al. 2012; Reddy et al. 2007).

Use of antibiotic selection for plasmid maintenance is impractical for certain experimental culture conditions or for in planta studies.

Corresponding author: L. P. Burbank; E-mail address: lindsey.burbank@ars.usda.gov

*The $\boldsymbol{e}$-Xtra logo stands for "electronic extra" and indicates that one supplementary figure, one supplementary table, and one supplementary appendix are published online.

http://dx.doi.org/10.1094/PHYTO-02-16-0097-R

This article is in the public domain and not copyrightable. It may be freely reprinted with customary crediting of the source. The American Phytopathological Society, 2016.
Toxin-antitoxin (TA) systems are an alternative mechanism for plasmid stability in a wide range of bacterial species in the natural environment. Also known as plasmid addiction systems, TA systems consist of a stable toxin molecule and a cognate antitoxin (either protein or RNA) which prevents toxin-mediated growth inhibition or cell death (Unterholzner et al. 2013). For plasmid-encoded TA systems, maintenance of the plasmid is necessary to ensure continuous production of an unstable antitoxin. TA systems are categorized based on antitoxin mode of action. Type II TA systems are defined by a protein antitoxin that interacts with the toxin posttranslation, inhibiting toxin activity (Blower et al. 2011; Syed and Lévesque 2012). Type II TA systems can be found on plasmids or on bacterial chromosomes and, in some cases, regulate bacterial growth rate and cell dormancy (Syed and Lévesque 2012).

PemI/PemK is a type II TA system originally described for its role in stable inheritance of Escherichia coli plasmid R100 (Tsuchimoto et al. 1988, 1992). Toxin PemK inhibits cell growth by acting as an endoribonuclease, and antitoxin PemI prevents PemK activity by direct binding (Lee et al. 2012; Zhang et al. 2004). PemI is a target for cellular proteases, and requires continuous production to be maintained at a functional level (Zhang et al. 2004). A PemI/PemK homolog found on a large plasmid in X. fastidiosa strain Riv11 functions in a similar manner, contributing to plasmid stability in $X$. fastidiosa (Lee et al. 2010, 2012). The previously described shuttle vector pXf20pemIK (Lee et al. 2010) contains an oriV origin of replication and replication initiator protein TrfA for propagation in $X$. fastidiosa (Stenger and Lee 2011). Addition of the PemI/PemK TA system caused $\mathrm{pXf20pemIK}$ to be maintained in $X$. fastidiosa subsp. fastidiosa Temecula-1 for multiple generations in the absence of antibiotic selection in vitro (Lee et al. 2010). Suitability of pXf20pemIK for complementation and in planta experiments has not been determined previously.

In this study, we expanded characterization of the PemI/PemK plasmid addiction system as a stability factor for plasmid complementation vectors to be used in $X$. fastidiosa virulence studies in grapevine. Two vectors described here, pXf20pemIK and broad-host-range 
vector $\mathrm{pBBR5}$ pemIK, are effective for mutant complementation in $X$. fastidiosa and also are able to replicate in multiple bacterial species, providing a versatile tool for genetic studies in vivo.

\section{MATERIALS AND METHODS}

Bacterial strains, growth conditions, and transformation. All bacterial strains and plasmid constructs are listed in Table 1. Competent cells, cloning vectors, and reagents were purchased from Thermo Fisher Scientific unless otherwise specified. Restriction endonucleases were purchased from New England Biolabs. E. coli Top10 was used as a cloning host and for plasmid stability analysis. E. coli $c c d B$ Survival $2 \mathrm{~T}^{\mathrm{R}}$ was used for propagation of Gateway vectors. E. coli strains were grown in Luria-Bertani (LB) medium at $37^{\circ} \mathrm{C}$ with addition of antibiotics when necessary. For $E$. coli, antibiotics were used at the following concentrations: ampicillin at $100 \mu \mathrm{g} / \mathrm{ml}$, kanamycin at $30 \mu \mathrm{g} / \mathrm{ml}$, chloramphenicol at $35 \mu \mathrm{g} / \mathrm{ml}$, and gentamycin at $10 \mu \mathrm{g} / \mathrm{ml}$. X. fastidiosa strains Stag's Leap (subsp. fastidiosa) and Dixon (subsp. multiplex), and mutant derivatives were grown in PD3 medium at $28^{\circ} \mathrm{C}$ (Davis et al. 1981). For $X$. fastidiosa strains, PD3 was supplemented when necessary with kanamycin, gentamycin, or chloramphenicol, at a concentration of $5 \mu \mathrm{g} / \mathrm{ml}$. Xanthomonas campestris pv. campestris strain 8004 and Pseudomonas syringae pv. tomato DC3000 were grown at $28^{\circ} \mathrm{C}$ in $\mathrm{LB}$ medium supplemented with kanamycin $(30 \mu \mathrm{g} / \mathrm{ml})$ or gentamycin $(10 \mu \mathrm{g} / \mathrm{ml})$ when necessary.

Xylella fastidiosa was transformed by electroporation (Guilhabert et al. 2001). Plasmid DNA was treated with M.SssI CpG methyltransferase (New England Biolabs) prior to transformation to improve efficiency (Matsumoto and Igo 2010). Xanthomonas campestris pv. campestris,
P. syringae pv. tomato, and E. coli were transformed by electroporation using cells prepared as follows. Cells were grown in LB medium to a cell density of optical density at $600 \mathrm{~nm}\left(\mathrm{OD}_{600}\right)=0.3$ and harvested by centrifugation. Cells were washed twice in sterile distilled $\mathrm{H}_{2} \mathrm{O}$ and twice in $10 \%$ glycerol and resuspended in $10 \%$ glycerol to $1 / 10$ of the original volume.

Plasmid vector construction. Previously described plasmids pBBR1-MCS5 (Kovach et al. 1995) and pXf20pemIK (Lee et al. 2010) were modified in the following manner. pBBR5pemIK was constructed by insertion of a 700-bp fragment containing the pemI/pemK open reading frames and native promoter excised from pXf20pemIK using EcoRI. Gateway cloning versions of pXf20pemIK and pBBR5pemIK vectors were created using a Gateway vector conversion kit following the manufacturer's instructions. Briefly, Gateway cassette version A was cloned into the EcoRV site of pXf20pemIK or the SmaI site of pBBR5pemIK to create pXf20pemIK-GW and pBBR5pemIK-GW, respectively. All plasmids were sequenced in entirety to confirm all modifications and locations of unique restriction endonuclease sites.

Mutant $\Delta c \operatorname{csp} 1$ complemented strains. A cold shock protein homolog (Csp1) was previously characterized (Burbank and Stenger 2016) for its role in cold response and virulence in Xylella fastidiosa. A knockout mutant $(\Delta c s p l)$ was used to evaluate effectiveness of plasmid vectors for complementation analysis in both in vitro and in planta experiments. All polymerase chain reaction (PCR) primer sequences used are listed in Supplementary Table S1 and PCR conditions are listed in Supplementary Appendix S1. The genome sequence of $X$. fastidiosa Temecula-1 (Van Sluys et al. 2003) was used for reference in the absence of the full genome sequence of the closely

TABLE 1. Strains and plasmids used in this study

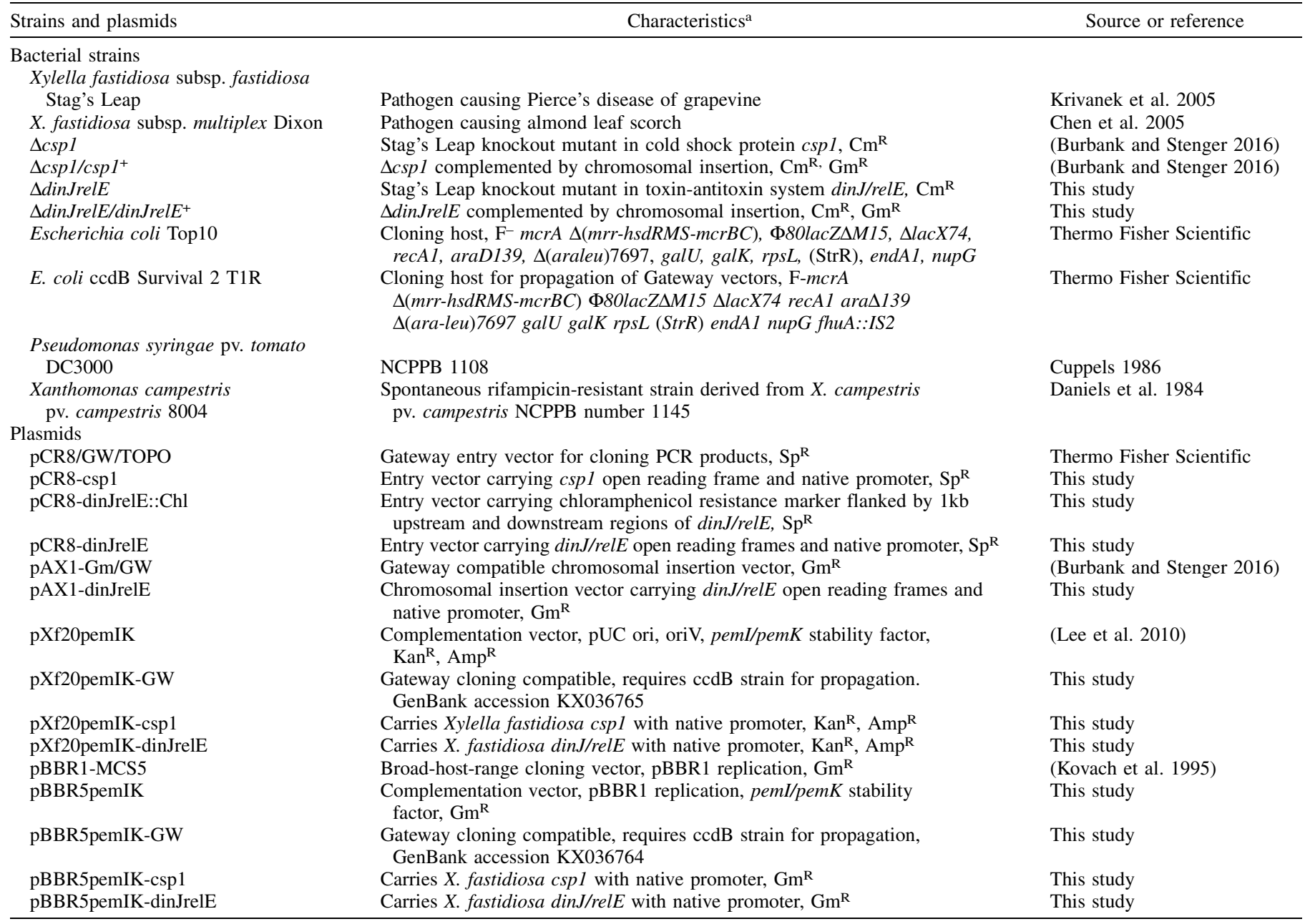

${ }^{a} \mathrm{Cm}^{\mathrm{R}}, \mathrm{Sp}^{\mathrm{R}}, \mathrm{Amp}^{\mathrm{R}}, \mathrm{Kan}^{\mathrm{R}}$, and $\mathrm{Gm}^{\mathrm{R}}$ indicate resistance to chloramphenicol, spectinomycin, ampicillin, kanamycin, and gentamycin, respectively. 
related Stag's Leap strain. Construction of knockout mutant $\Delta$ cspl and complemented strain $\Delta c s p 1 / c s p 1^{+}$has been previously described (Burbank and Stenger 2016). For plasmid complemented strains, the open reading frame of $\operatorname{csp} 1$ (Temecula-1 locus tag PD1380) was PCR amplified and cloned into pCR8/GW/TOPO to create plasmid pCR8-csp1. This construct was recombined with pXf20pemIKGW and pBBR5pemIK-GW to create plasmids pXf20pemIK-csp1 and pBBR5pemIK-csp1, respectively. Complementation plasmids were transformed into $\Delta \operatorname{cspl}$ by electroporation (Guilhabert et al. 2001).

$\Delta$ dinJrelE mutant and complemented strains. To further assess plasmid effects on gene expression level, an unrelated mutant ( $\triangle$ dinJrelE) and plasmid complemented strains were evaluated for gene expression level. This double knockout mutant was created in two adjacent genes, dinJ and relE (locus tag PD1099-PD1100) encoding a TA system previously characterized in $X$. fastidiosa Temecula-1 (Lee et al. 2014). DNA fragments (1 kb) upstream and downstream of dinJrelE were PCR amplified using Stag's Leap genomic DNA as template and primer pairs dinJUpfwd/dinJUpRevChl and relEDnFwdChl/relEDnRev. A chloramphenicol resistance cassette from the Tn5 HyperMu transposon (Epicentre) was PCR amplified separately using primers Chlfwd and Chlrev. Primers dinJUpRevChl and relEDnFwdChl contain 15 bp of sequence homologous to the chloramphenicol resistance marker. All three DNA fragments (upstream and downstream flanking regions and chloramphenicol resistance marker) were annealed and assembled using overlap extension PCR (Heckman and Pease 2007). PCR conditions are listed in Supplementary Appendix S1. The combined PCR product of approximately $3 \mathrm{~kb}$ was gel purified and cloned into vector $\mathrm{pCR} 8 / \mathrm{GW} / \mathrm{TOPO}$, following the manufacturer's instructions, to create pCR8-dinJrelE::chl. This plasmid was transformed into $X$. fastidiosa by electroporation. Homologous recombination and gene replacement were selected for by plating transformants on PD3 with chloramphenicol. Chloramphenicolresistant colonies were screened by colony PCR using primer sets RST31/RST33 (Minsavage et al. 1994) (X.fastidiosa-specific primers)

A

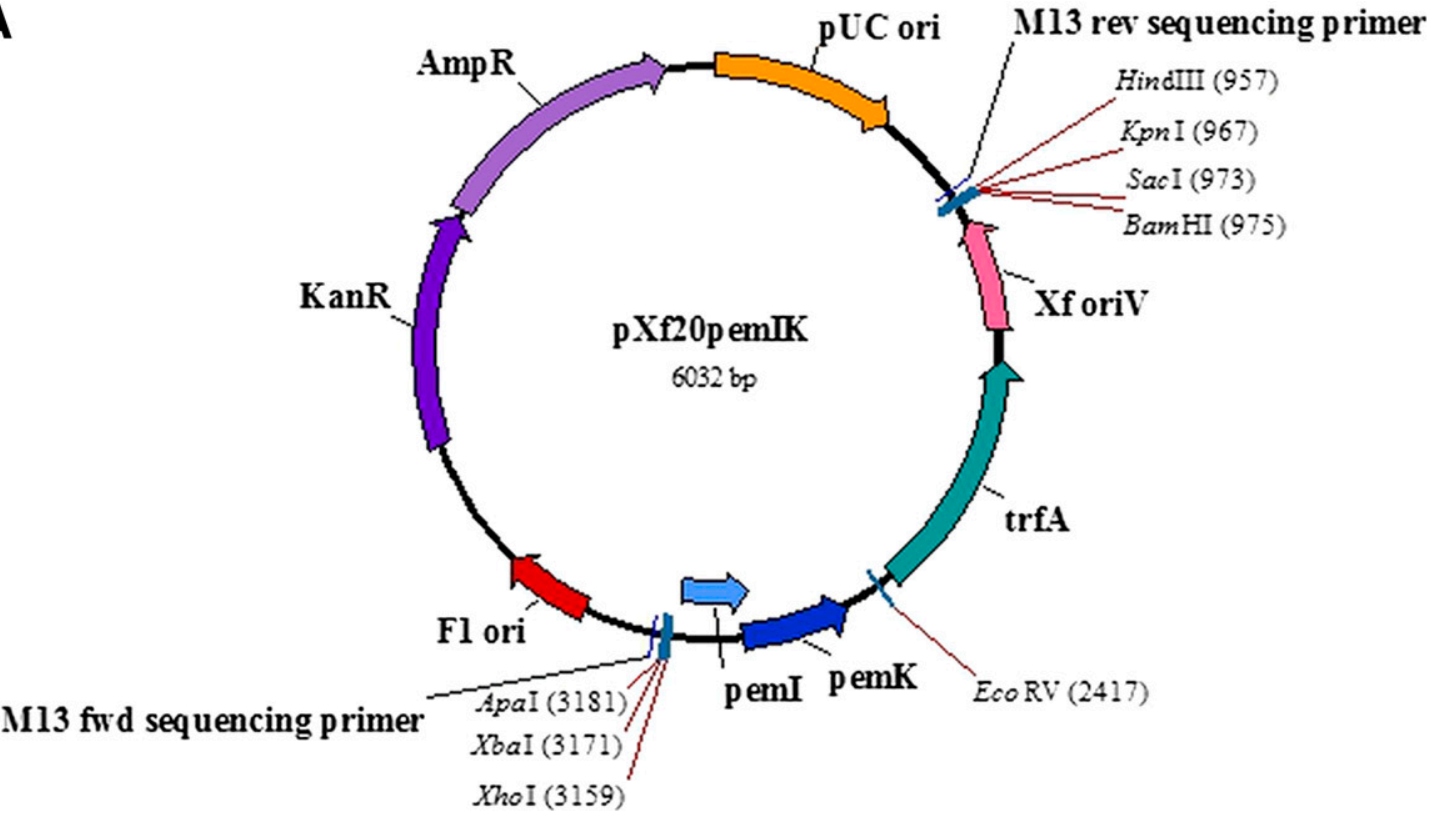

B

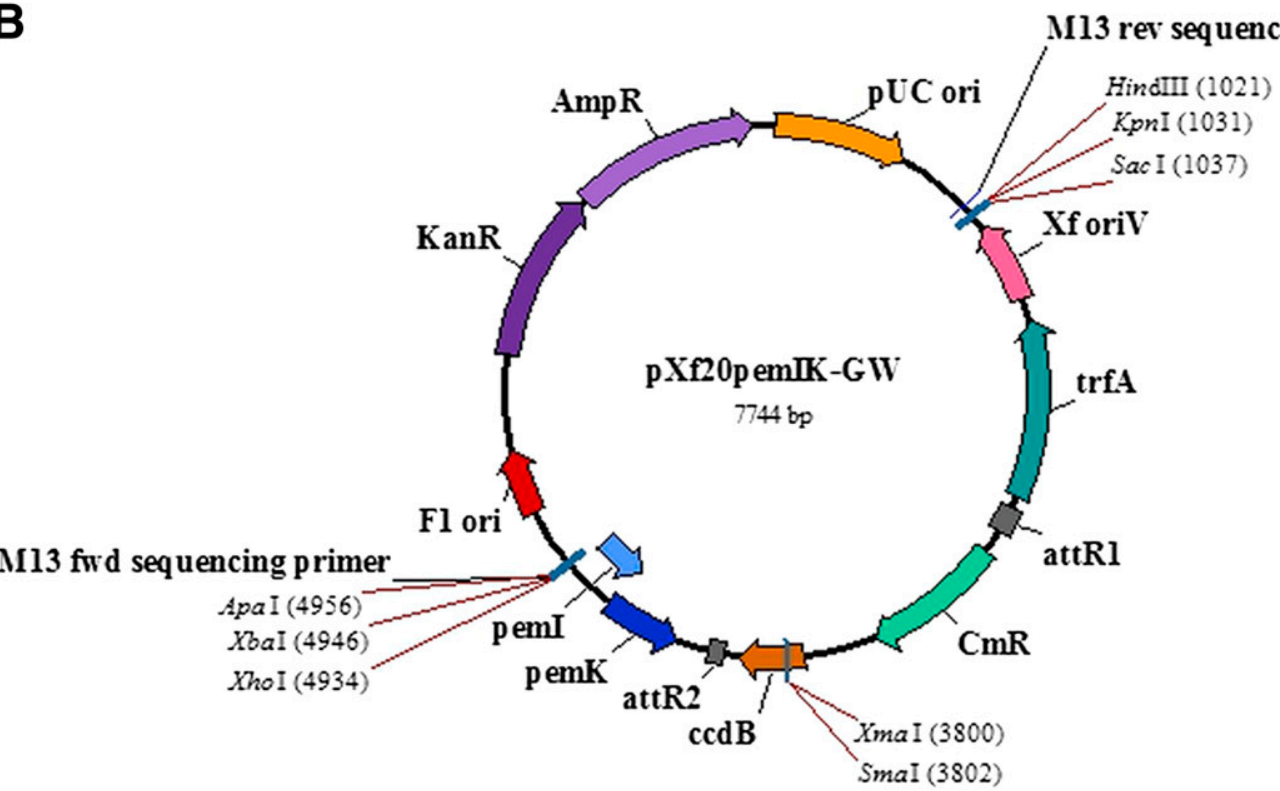

Fig. 1. Map and characteristics of pXf20pemIK. A. Plasmid pXf20pemIK containing the minimum replicon from native plasmid isolated from strain Riv11, and Escherichia coli cloning vector replication elements and antibiotic markers from pCR2.1 (Thermo Fisher Scientific); and B, Gateway cloning-compatible derivative of pXf20pemIK. All listed restriction sites are unique. Plasmid maps were created using Vector NTI Advance software (Thermo Fisher Scientific). 
and dinJrelEcheckfwd/dinJrelEcheckrev (gene-specific primers). Correct mutants ( $\triangle$ dinJrelE) were further confirmed by cloning and sequencing the site of recombination. For complementation of mutant $\Delta$ dinJrelE, a DNA fragment containing the $\operatorname{dinJ} / \mathrm{relE}$ open reading frames and 250 bp upstream and downstream (to include all native promoter and terminator sequences) was PCR amplified using primers dinJrelEfwd/dinJrelErev and cloned into vector pCR8/GW/TOPO following the manufacturer's instructions, creating pCR8-dinJrelE. This plasmid was recombined with Gatewaycompatible insertion vector pAX1-Gm-GW (Burbank and Stenger 2016; Matsumoto et al. 2009) according to the manufacturer's protocol for Gateway cloning to create construct pAX1-dinJrelE. This suicide plasmid was transformed into mutant $\Delta$ dinJrelE by electroporation; recombination into a chromosome neutral site was confirmed by cloning and sequencing the site of recombination. The resulting complemented strain was called $\Delta$ dinJrelE/ dinJrelE $E^{+}$. Plasmid complemented strains bearing dinJrelE were created in the same manner as described for $\operatorname{csp} 1$ complemented strains. pCR8-dinJrelE was recombined with pXf20pemIK and pBBR5pemIK to create pXf20pemIK-dinJrelE and pBBR5pemIKdinJrelE, respectively.

Plasmid stability in vitro. To determine plasmid stability in $X$. fastidiosa, wild-type strains (Stag's Leap and Dixon) carrying empty-vector plasmids pBBR5pemIK and pXF20pemIK were grown in PD3 medium with or without antibiotics and subcultured every 7 days for a total of five consecutive passages. Aliquots were diluted and plated on PD3 with and without antibiotic selection. Colonies were quantified after 10 days of incubation at $28^{\circ} \mathrm{C}$. Percent plasmid retention was determined based on number of antibioticresistant CFU divided by total CFU. To determine plasmid stability in E. coli, P. syringae pv. tomato, and Xanthomonas campestris pv. campestris, cells were grown in LB medium with or without antibiotics and subcultured every $24 \mathrm{~h}$ for $E$. coli or $48 \mathrm{~h}$ for $P$. syringae pv. tomato and $X$. campestris pv. campestris. After each subculture, percentage of cells retaining the plasmid were quantified in the same manner as for Xylella fastidiosa.

Copy number. $X$. fastidiosa strains carrying empty vectors pXf20pemIK or pBBR5pemIK were grown in PD3 for 1 week. E. coli, $P$. syringae pv. tomato, and Xanthomonas campestris pv. campestris were grown in LB medium overnight (for E. coli) or for $48 \mathrm{~h}$ (P. syringae pv. tomato and $X$. campestris pv. campestris). Total DNA was extracted from all strains using a Dneasy Blood and Tissue Kit (Qiagen) following the manufacturer's protocol. DNA samples were diluted 1:10 and 2- $\mu$ l aliquots were used as template for quantitative PCR (qPCR) with AB SYBR Green Master Mix. Plasmid quantity was determined based on a standard curve of known concentrations of the purified plasmids using primers pemIKfwd/ pemIKrev, targeting the pemK open reading frame for amplification. For strains carrying both pXf20pemIK and pBBR5pemIK, alternate sets of primers were used to target the unique antibiotic markers on the different plasmids (kanfwd/kanrev and gmfwd/gmrev). Primers used for genome quantification targeted a gene or region known to be

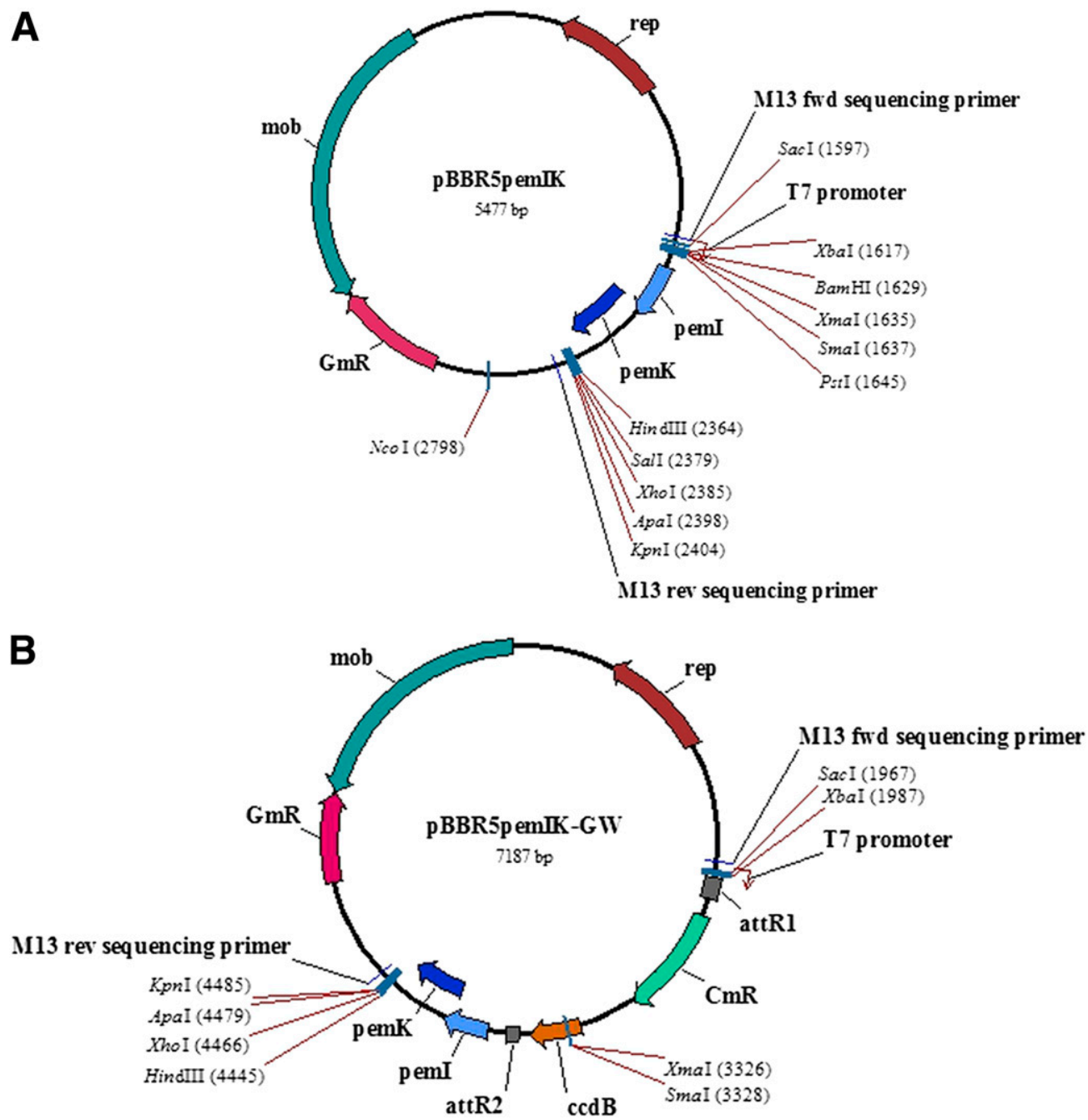

Fig. 2. Map and characteristics of pBBR5pemIK. A, pBBR5pemIK, created by addition of the pemI/pemK toxin-antitoxin system sequence to broad-host-range vector pBBR1-MCS5 and B, Gateway compatible derivative. All listed restriction sites are unique. Plasmid maps were created using Vector NTI Advance software (Thermo Fisher Scientific). 
present in a single copy on the bacterial chromosome: $g y r B$ for $X y l e l l a$ fastidiosa and $P$. syringae, rpoB for Xanthomonas campestris, and $d x s$ for $E$. coli. Primers to determine genome quantity were as follows: XfgyrBfwd/XfgyrBrev (Xylella fastidiosa), dxsfwd/dxsrev (E. coli), rpoBfwd/rpoBrev (Xanthomonas campestris pv. campestris), and PsgyrBfwd/PsgyrBrev (P. syringae pv. tomato). Copy number per genome was calculated based on size and quantity of both the bacterial chromosome and plasmid, as described (Lee et al. 2006).

Gene-expression analysis. Total RNA was extracted from cells after 7 days of growth on PD3 plates with or without the appropriate antibiotics using the hot phenol extraction method described by Jahn et al. (2008). RNA samples were treated with Turbo Dnase and RNA integrity was evaluated by agarose gel electrophoresis. Total RNA $(1 \mu \mathrm{g})$ was used to make cDNA using an iScript cDNA synthesis kit (Bio-Rad). qPCR was performed using AB SYBR Green Master Mix and primer pairs csp1fwd/csp1rev and dinJfwd/dinJrev for quantification of $c s p l$ and $\operatorname{din} J$, respectively. Relative gene expression was normalized to reference gene $d n a Q$ (primers dnaQfwd/dnaQrev). DnaQ expression was observed to be stable in different mutants tested and also has been described previously as a reference gene in Xylella fastidiosa gene-expression studies (Zaini et al. 2008). Gene-expression analysis was performed on at least three independent biological replicates for each strain, with three PCR replicates for each.

Cold tolerance. $X$. fastidiosa strains were grown on PD3 plates for 7 days at $28^{\circ} \mathrm{C}$. Cells were harvested by scraping off plates and resuspended in sterile $1 \times$ phosphate-buffered saline (PBS). Starting cell density was normalized by measuring $\mathrm{OD}_{600}$ and adjusting the concentration to $\mathrm{OD}_{600}=0.1$ with $1 \times$ PBS. A $1-\mathrm{ml}$ aliquot of cells from each strain was removed and serial dilutions were plated on PD3 to serve as an untreated control. Cold-treated samples were kept at $4^{\circ} \mathrm{C}$ for $24 \mathrm{~h}$ and then serial dilutions were plated on PD3. Colonies were counted for quantification after 10 days of incubation at $28^{\circ} \mathrm{C}$. Percent survival indicated number of CFU in treated samples divided by number of CFU in the untreated control, presented as the mean of at least three independent experiments, each consisting of three biological replicates.

Virulence assay. Grapevines (Vitis vinifera 'Chardonnay') were inoculated with wild-type Stag's Leap, $\Delta \operatorname{cspl} 1, \Delta \operatorname{csp} 1 / \operatorname{csp} 1^{+}, \Delta \operatorname{cspl}$ pBBR5pemIK-cspl, $\Delta$ cspl pXf20pemIK-cspl, and empty-vector controls using the needle inoculation method previously described (Hill and Purcell 1995; Roper et al. 2007). Plants were observed for symptom development weekly and assigned a disease rating on a scale of 0 to 5 (Roper et al. 2007). Bacterial quantity was determined by qPCR. Total DNA was extracted from grapevine petioles $15 \mathrm{~cm}$ above the point of inoculation 12 weeks postinoculation. qPCR was performed using AB SYBR Green Master Mix following the manufacturer's instructions, with $5 \mu$ of total DNA as template and primer set XF145-60fwd/XF145-60rev for X. fastidiosa detection (Ledbetter and Rogers 2009). PCR conditions are listed in Supplementary Appendix S1. Quantity of X. fastidiosa was determined based on a standard curve of wild-type Stag's Leap genomic DNA, and normalized to total DNA concentration.

Plasmid stability in planta. Grapevines were inoculated with wild-type $X$. fastidiosa Stag's Leap as well as strains carrying emptyvector plasmids pBBR1-MCS5, pBBR5pemIK, and pXf20pemIK using the same method as described for virulence assays. Petioles (3 petioles/plant) were removed from symptomatic leaves after 14 weeks postinoculation and tissue weight was recorded. Petioles were surface sterilized by successive washing in $70 \%$ ethanol for $30 \mathrm{~s}$ and $20 \%$ bleach for $30 \mathrm{~s}$, and rinsed twice in sterile water for $30 \mathrm{~s}$. Tissue was ground in $2 \mathrm{ml}$ of sterile $1 \times$ PBS and serial dilutions were plated on PD3 plates with and without antibiotics. Colonies were quantified after 1 week of growth at $28^{\circ} \mathrm{C}$ and normalized to original tissue weight. Percentage of cells retaining the plasmid was determined by the number of antibiotic-resistant CFU divided by total CFU. Ten plants were sampled for each strain and dilution plating was performed on triplicate samples from each plant.
Tests for statistical significance. Significance of quantitative differences among treatments was determined using one-way analysis of variance followed by a Tukey-Kramer multiple comparison test $(\alpha=0.05)$. All statistical analyses were performed using Origin 2015 graphing and analysis software (OriginLab Inc.).

\section{RESULTS}

Expression of PemI/PemK on plasmid vectors increases stability. A modified version of pXf20pemIK (Lee et al. 2010) (pXf20pemIK-GW, GenBank accession KX036765) was created by adding a Gateway cloning cassette (Walhout et al. 2000) to increase versatility of the vector by eliminating the need for restriction endonuclease cloning (Fig. 1). In addition, a broad-host-range vector was constructed to further explore utility of the PemI/PemK addiction system for plasmid stability in a wider range of bacterial species, using pBBR1-MCS5 (Kovach et al. 1995) as a vector backbone. pBBR1-MCS5 alone is able to replicate in X. fastidiosa, although it is lost after extended incubation or growth in planta (Matsumoto et al. 2009, 2012; Reddy et al. 2007). Addition of the pemI/pemK sequence downstream of the multiple cloning site created pBBR5pemIK (Fig. 2). A Gateway cloning-compatible version (pBBR5pemIKGW, GenBank accession KX036764) also was created by insertion of a Gateway cassette into the multiple cloning site (Fig. 2). These two plasmids, pXf20pemIK and pBBR5pemIK, as well as Gatewaycompatible derivatives were used for characterization as complementation vectors in $X$. fastidiosa.

Vectors pXf20pemIK and pBBR5pemIK are both stable in $X$. fastidiosa but vary in host range and copy number. Vectors were transformed into several gram-negative bacterial species to assess host range and plasmid stability without antibiotic selection. Plasmid pXf20pemIK was stable for replication in E. coli and $X$. fastidiosa Stag's Leap but otherwise had a limited host range, especially in the absence of antibiotic selection (Table 2), which is consistent with previous findings (Lee et al. 2010). pXf20pemIK also did not replicate in $X$. fastidiosa Dixon, a strain belonging to the multiplex subspecies which causes almond leaf scorch (Table 2). pBBR5pemIK was able to replicate in all species and strains tested. Copy numbers of pemI/pemK carrying vectors were evaluated in different host species using a qPCR method (Lee et al. 2006). pXf20pemIK replicates at a high copy number in $E$. coli due to the pUC origin (Table 3). In X. fastidiosa, pXf20pemIK replicates at a lower copy number based on indigenous $X$. fastidiosa oriV. pBBR5pemIK, in addition to having a broad host range, consistently replicates at a medium to low copy number in all host species studied, both with and without antibiotic selection (Table 3).

Vectors pBBR5pemIK and pXf20pemIK are compatible in $\boldsymbol{E}$. coli and $\boldsymbol{X}$. fastidiosa. Compatibility of pBBR5pemIK and pXf20pemIK for cotransformation was assessed in both E. coli and $X$. fastidiosa. E. coli already carrying pBBR5pemIK was transformed with $\mathrm{pXf} 20$ pemIK by electroporation. E. coli transformants resistant to both kanamycin and gentamycin (from resistance encoded by pBBR5pemIK and pXf20pemIK, respectively) were selected and colonies were found to contain both plasmids based on restriction endonuclease digestion (Supplementary Figure S1). E. coli strains containing both plasmids were subcultured every $24 \mathrm{~h}$ for a total of five times without antibiotic selection and evaluated for retention of the plasmids by plating on selective media containing either kanamycin or gentamycin. Retention of pBBR5pemIK was close to $100 \%$ whereas pXf20pemIK was only present in a small percentage of cells (13\%) (Fig. 3). In the presence of antibiotic selection, the copy number of pXf20pemIK was $113 \pm 38$ in E. coli carrying both plasmids, based on qPCR. Under the same conditions, the copy number of pBBR5pemIK was $22 \pm 4.3$.

To determine compatibility of pXf20pemIK and pBBR5pemIK in $X$. fastidiosa, wild-type Stag's Leap carrying pXf20pemIK was transformed with pBBR5pemIK by electroporation. Transformants were recovered from selective plates containing both kanamycin 
and gentamycin and the presence of both plasmids was confirmed by restriction endonuclease digestion. Similar to what was observed in E. coli, pBBR5pemIK was still present in $100 \%$ of $X$. fastidiosa colonies. pXf20pemIK was retained by $50 \%$ of $X$. fastidiosa colonies after five subcultures (Fig. 3). The copy number of pXf20pemIK was reduced to $1.5 \pm 0.74$ in $X$. fastidiosa carrying both plasmids grown with antibiotic selection. pBBR5pemIK copy number was not affected by the presence of pXf20pemIK. In both $E$. coli and X. fastidiosa, the presence of the two plasmids simultaneously was confirmed by plasmid extraction and restriction endonuclease digestion (Supplementary Fig. S1).

pBBR5pemIK and pXf20pemIK are effective complementation vectors in $\boldsymbol{X}$. fastidiosa. Suitability of $\mathrm{pXf} 20 \mathrm{pemIK}$ and pBBR5pemIK for complementation was evaluated using a previously characterized $X$. fastidiosa knockout mutant, $\Delta c s p l$ (Burbank and Stenger 2016). Mutant $\Delta \operatorname{cspl}$ contains a deletion in a cold shock protein homolog and is less tolerant of cold temperatures, showing reduced survival rates after incubation at $4^{\circ} \mathrm{C}$. To compare the merit of plasmid complementation with previously described

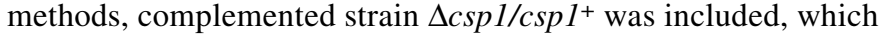
contains a chromosomal insertion of $\operatorname{cspl}$ at a neutral location (Matsumoto et al. 2009). Plasmids pXf20pemIK and pBBR5pemIK, containing a wild-type copy of $c s p l$ (including its native promoter), were evaluated for phenotypic complementation of $\Delta c s p 1$. Survival rates of wild-type Stag's Leap, $\Delta c s p 1$, and plasmid-complemented strains were quantified following cold treatment at $4^{\circ} \mathrm{C}$ for $24 \mathrm{~h}$ (Fig. 4). Both plasmid-complemented strains did not differ significantly from the wild-type survival rate (Fig. 4), equivalent to the complemented strain $\Delta c s p 1 / c s p 1^{+}$(Burbank and Stenger 2016). Strain $\Delta c s p 1$ carrying emptyvector $\mathrm{pBBR} 5$ pemIK and $\mathrm{pXf} 20$ pemIK did not show complementation. All strains were grown without antibiotic selection for the duration of the experiment. These results demonstrate the utility of PemI/PemKstabilized vectors for complementation experiments in vitro.

Plasmid impact on gene expression. Gene expression at the transcriptional level was compared for cspl in wild-type Stag's Leap,

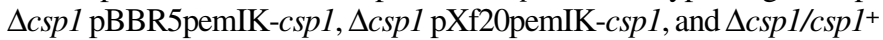
to determine whether there were effects due to expression on the

TABLE 2. Plasmid host range and stability in vitro ${ }^{a}$

\begin{tabular}{|c|c|c|c|c|}
\hline \multirow[b]{2}{*}{ Bacteria } & \multicolumn{2}{|c|}{ pXf20pemIK } & \multicolumn{2}{|c|}{ pBBR5pemIK } \\
\hline & + Kan & - Kan & $+\mathrm{Gm}$ & $-\mathrm{Gm}$ \\
\hline Xylella fastidiosa Stags Leap & + & + & + & + \\
\hline$X$. fastidiosa Dixon & - & - & + & + \\
\hline Escherichia coli & + & + & + & + \\
\hline Pseudomonas syringae & & & & \\
\hline pv. tomato & + & - & + & + \\
\hline Xanthomonas campestris & & & & \\
\hline pv. campestris & - & - & + & + \\
\hline
\end{tabular}

TABLE 3. Plasmid copy number ${ }^{\mathrm{a}}$

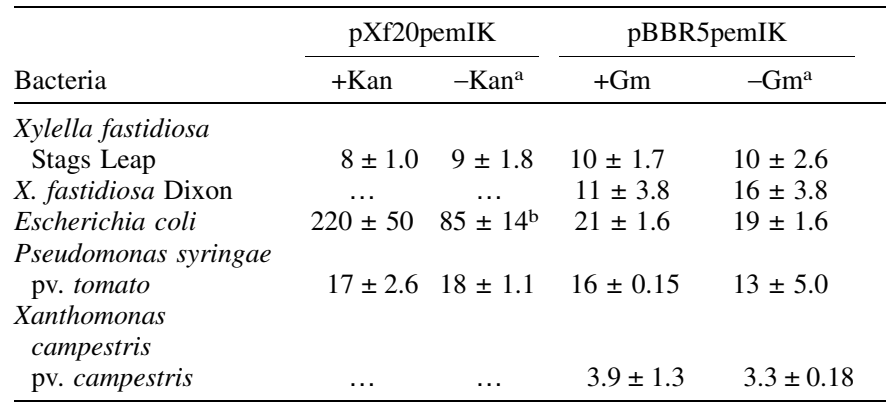

a Copy number is reported for growth after one generation.

b Significantly different from copy number in the presence of antibiotic selection based on Student's $t$ test $(P \leq 0.05)$. plasmids (Table 4). Although $\operatorname{cspl}$ expression in $\Delta \operatorname{csp} 1 / \operatorname{csp} 1^{+}$was equivalent to wild-type levels, expression in $\Delta c s p 1$ pBBR5pemIKcspl and $\Delta$ cspl pXf20pemIK-cspl was 50-fold higher (Table 4). However, this increase is most likely due to the regulation of cspl specifically, because this gene shows constitutively high expression at the translational level as well (Burbank and Stenger 2016). Expression analysis of a different gene $(\operatorname{din} J)$ showed a much smaller increase (fivefold) in plasmid-complemented strains compared with the wild type or a chromosomal insertion (Table 4). DinJ is an antitoxin that functions as part of the DinJ/RelE TA system (Lee et al. 2014). DinJ homologs have demonstrated autoregulation by direct binding to the dinJ promoter region. This regulatory feedback would reduce the increase in expression caused by a multicopy plasmid.

PemI/PemK conveys long-term stability to plasmids in planta. Stability of pBBR5pemIK and pXf20pemIK in wild-type $X$. fastidiosa Stag's Leap were evaluated after 14 weeks postinoculation in grapevines inoculated by a pin prick on the stem. The original pBBR1MCS5 vector without addition of the pemI/pemK sequence also was included for comparison. pXf20 (prior to addition of pemI/pemK) was not stable after several generations in vitro (Lee et al. 2010) and, therefore, was not tested in planta. Bacterial populations isolated from plants inoculated with wild-type Stag's Leap, pBBR1-MCS5, pBBR5pemIK, and pXf20pemIK were compared to determine whether carrying the plasmids had any fitness cost during growth in the plant (Fig. 5A). There was no significant difference in bacterial population between the different strains, suggesting that the plasmid empty vectors do not affect growth and replication of $X$. fastidiosa in the plant (Fig. $5 \mathrm{~A})$. Percentage of bacterial population retaining the plasmid was quantified by growing $X$. fastidios $a$ populations isolated from infected plant tissue in the presence and absence of antibiotics. Restriction enzyme digestion confirmed the presence of the plasmid in antibioticresistant colonies (data not shown). pXf20pemIK and pBBR5pemIK were retained at 98 and 95\%, respectively (Fig. 5B), while pBBR1MCS5 lacking pemI/pemK was not present in any isolated colonies. These results indicate that PemI/PemK is an effective addiction system for plasmid maintenance during bacterial growth in the plant host.

pXf20pemIK and pBBR5pemIK are effective complementation vectors in planta. $\mathrm{pXf} 20$ pemIK and $\mathrm{pBBR} 5 \mathrm{pemIK}$ were evaluated for suitability as complementation vectors for virulence studies in $X$. fastidiosa using the $\Delta c s p 1$ mutant, which is still pathogenic in grapevine but shows reduced symptom development. After 12 weeks postinoculation, symptom development was quantified using a 0-to-5 rating scale (Roper et al. 2007). Plants

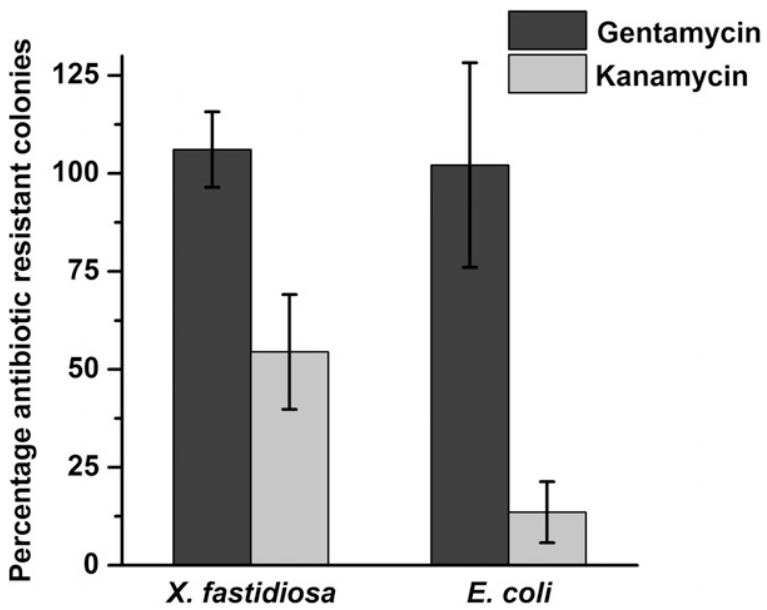

Fig. 3. Plasmid stability following cotransformation of $\mathrm{pXf} 20 \mathrm{pemIK}$ and pBBR5pemIK. Percentage of antibiotic-resistant colonies after five consecutive subcultures without antibiotic selection of Xylella fastidiosa and Escherichia coli carrying both plasmids pXf20pemIK (KanR) and pBBR5pemIK (GmR). Percentage of cells still retaining the plasmids were determined by antibiotic-resistant CFU divided by total CFU. Bars represent the mean of at least three independent biological replicates plated in duplicate. Error bars indicate standard deviation. 
inoculated with $\Delta \operatorname{cspl}$ carrying complementation constructs $\mathrm{pXf} 20 \mathrm{pe}-$ mIK-cspl or pBBR5pemIK-cspl had average disease scores, equivalent to wild-type inoculated plants (Fig. 6A). Plants inoculated with $\Delta c s p 1$ transformed with empty vectors $\mathrm{pXf} 20$ pemIK or $\mathrm{pBBR} 5$ pemIK did not differ significantly from those inoculated with $\Delta c s p 1$, confirming that empty vectors alone do not have a phenotypic effect on X. fastidiosa in the plant (Fig. 6A). Mutant $\Delta$ cspl also has been shown to have a lower bacterial quantity in inoculated plants as compared with wild-type $X$. fastidiosa Stag's Leap (Burbank and Stenger 2016). Bacterial populations were quantified by qPCR of total DNA extracted from petioles of inoculated plants (Fig. 6B). Plants inoculated with $\Delta c s p 1$ pXf20pemIK-cspl and $\Delta c s p 1$ pBBR5pemIK-cspl showed an increase in bacterial quantity as compared with the mutant $\Delta c s p 1$. Plants inoculated with $\Delta c s p 1$ carrying empty vectors pXf20pemIK or pBBR5pemIK had bacterial quantities equivalent to $\Delta c s p 1$ alone (Fig. 6B). These results demonstrate the practical use of plasmids pXf20pemIK and pBBR5pemIK for complementation of $X$. fastidiosa mutants in planta.

\section{DISCUSSION}

Plasmid vectors that can be maintained by the cell in a stable manner under a variety of experimental conditions are essential to studies of bacterial genetics. Disease development in susceptible grapevines following inoculation with $X$. fastidiosa generally takes several months. For complementation of mutants altered in virulence or characterization of $X$. fastidiosa strains expressing exogenous proteins, use of plasmid vectors is limited to those that are stable without antibiotic selection for long periods of time in the plant environment.

Very few plasmids have been characterized that are supported for replication in $X$. fastidiosa, and even fewer are retained in the absence of selective pressure. Native plasmids are present in several environmental isolates of $X$. fastidiosa and are generally stable but, unmodified, are not suitable for use as cloning vectors because of

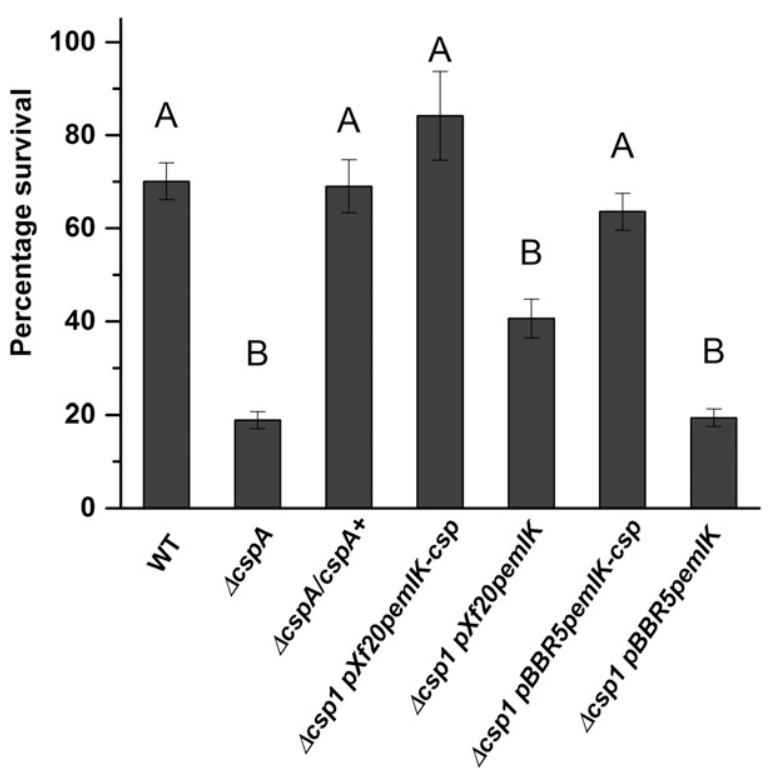

Fig. 4. Complementation of $\Delta c s p 1$ knockout mutant using plasmids vectors. Percent cell survival of Xylella fastidiosa was quantified based on counts of $\mathrm{CFU}$ before and after $24 \mathrm{~h}$ at $4^{\circ} \mathrm{C}$. Mean percent cell survival was compared for wild-type Stag's Leap (WT), a deletion mutant of cspl ( $\Delta \operatorname{cspl}$ ), $\Delta \operatorname{cspl}$ complemented by chromosomal insertion $\left(\Delta \operatorname{csp} 1 / \operatorname{csp} 1^{+}\right)$, and plasmid complemented strains $\Delta c s p 1$ pXf20pemIK-cspl and $\Delta$ cspl pBBR5pemIK-cspl. $\Delta c s p 1$ pXf20pemIK and $\Delta c s p 1$ pBBR5pemIK are empty-vector controls. Bars represent means ( \pm standard error) combined from three independent experiments, each consisting of three replicates plated in duplicate. Means with different letters are significantly different based on analysis of variance followed by a Tukey-Kramer multiple comparison test $(\alpha=0.05)$. size and lack of selectable markers (Lee et al. 2010; Rogers and Stenger 2012; Stenger et al. 2010). Combination of X. fastidiosa replication elements with an $E$. coli-compatible cloning vector presents one solution. Minimum replicon and PemI/PemK stability elements derived from a native $X$. fastidios a plasmid combined with commercially available cloning vector pCR2.1 (Thermo Fisher Scientific) was characterized previously as a potential vector for use in X. fastidiosa (pXf20pemIK) in vitro (Lee et al. 2010).

We demonstrate here that $\mathrm{pXf} 20$ pemIK is stable for up to 14 weeks during infection in grapevine, and can be used for phenotypic complementation both in vitro and in planta. This vector is somewhat limited in host range, possibly due to the presence of multiple replication origins. As a broad-host-range alternative, pBBR5pemIK, which utilizes the same TA system for plasmid retention, was developed. This vector is based on the pBBR1-MCS5 backbone, derived from a small native plasmid found in Bordetella brontiseptica (Antoine and Locht 1992). Plasmids based on pBBR1 have been demonstrated to replicate in E. coli, B. pertussis, Vibrio cholerae, Rhizobium meliloti, P. putida, X. fastidiosa, P. stewartii, and multiple Brucella spp. (Antoine and Locht 1992; Elzer et al. 1995; Kovach et al. 1995; Mohammadi et al. 2012; Reddy et al. 2007). Although relatively stable in the absence of antibiotic selection in some bacterial species (Elzer et al. 1995), during long-term growth of $X$. fastidiosa in planta, pBBR1-MCS5 is lost without selective pressure (Matsumoto et al. 2012). Therefore, greater stability of pBBR5pemIK due to the PemI/PemK TA system enhances its practical use for in planta experiments. Additionally, pBBR1-derived plasmids do not belong to any well-established incompatibility groups and, thus, may coexist with a number of other plasmids, including commonly used cloning and expression vectors (Antoine and Locht 1992). Ability of pBBR5pemIK and pXf20pemIK to be cotransformed in $X$. fastidiosa allows for the possibility of exogenous expression of more than one gene simultaneously.

Different strains of $X$. fastidiosa vary in plant host range and presence of different mobile genetic elements (de Mello Varani et al. 2008; Van Sluys et al. 2003). X. fastidiosa Stag's Leap belongs to subspecies fastidiosa, which includes strain Temecula-1 and other strains causing Pierce's disease of grapevine. Molecular virulence mechanisms of other subspecies such as multiplex (causing almond leaf scorch) and sandyi (causing oleander leaf scorch) are less well studied. pXf20pemIK was not stable after transformation into Dixon, suggesting a difference in native plasmids present in different $X$. fastidiosa subspecies that could interfere with replication of pXf20pemIK. In comparison, pBBR5pemIK has a broad host range, allowing for use in other $X$. fastidiosa strains beyond those of subspecies fastidiosa.

Gene expression level is an important consideration for complementation vectors because phenotypic anomalies can be created by over- or underexpression of the gene of interest. Significantly higher gene expression (50-fold) was observed for cspl carried on both

TABLE 4. Relative gene expression

\begin{tabular}{lcc}
\hline & \multicolumn{2}{c}{ Relative quantity $^{\mathrm{a}}$} \\
\cline { 2 - 3 } Strain & $c s p 1$ & $\operatorname{dinJ}$ \\
\hline Wild-type Stag's Leap & $1 \pm 0.00$ & $\mathrm{ND}$ \\
$\Delta \operatorname{csp1}$ & $0.02 \pm 0.02^{\mathrm{b}}$ & $\mathrm{ND}$ \\
$\Delta \operatorname{csp} 1 /$ csp1 & $\mathrm{ND}$ \\
$\Delta \operatorname{csp} 1$ pBBR5pemIK-csp1 & $1.13 \pm 0.78$ & $\mathrm{ND}$ \\
$\Delta \operatorname{csp} 1$ pXf20pemIK-csp1 & $54.26 \pm 4.70^{\mathrm{b}}$ & $\mathrm{ND}$ \\
Wild-type Stag's Leap & $50.24 \pm 4.85^{\mathrm{b}}$ & $1 \pm 0.00$ \\
$\Delta$ dinJrelE & $\mathrm{ND}$ & $0.015 \pm 0.01^{\mathrm{b}}$ \\
$\Delta$ dinJrelE/dinJrelE & $\mathrm{ND}$ & $1.66 \pm 0.70$ \\
$\Delta$ dinJrelE pBBR5pemIK-dinJrelE & $\mathrm{ND}$ & $5.54 \pm 1.82^{1}$ \\
$\Delta$ dinJrelE pXf20pemIK-dinJrelE & $\mathrm{ND}$ & $5.32 \pm 2.02^{1}$ \\
\hline
\end{tabular}

a $\mathrm{ND}=$ not determined.

b Significantly different relative to the wild-type expression level based on a Student's $t$ test $(P \leq 0.05)$. 
plasmids pBBR5pemIK and pXf20pemIK compared with the wild type. However, this is most likely due to transcriptional regulation of $\operatorname{csp} 1$ specifically because the effect was not seen with a different gene $($ dinJ). It is probable that $\operatorname{csp} 1$ does not have feedback regulation at the transcriptional level such that high expression results from multiple gene copies controlled by a constitutive promoter. Similar expression levels were seen regardless of which plasmid was used, suggesting that this increase was not due to readthrough activity from another upstream promoter. Equally high expression levels also were observed for cspl expressed on pBBR1-MCS5 (data not shown), implying that PemI/PemK activity is not affecting transcription of cspl. Expression of dinJ, which is autoregulated at the transcriptional level, was fivefold higher in plasmid complemented strains compared
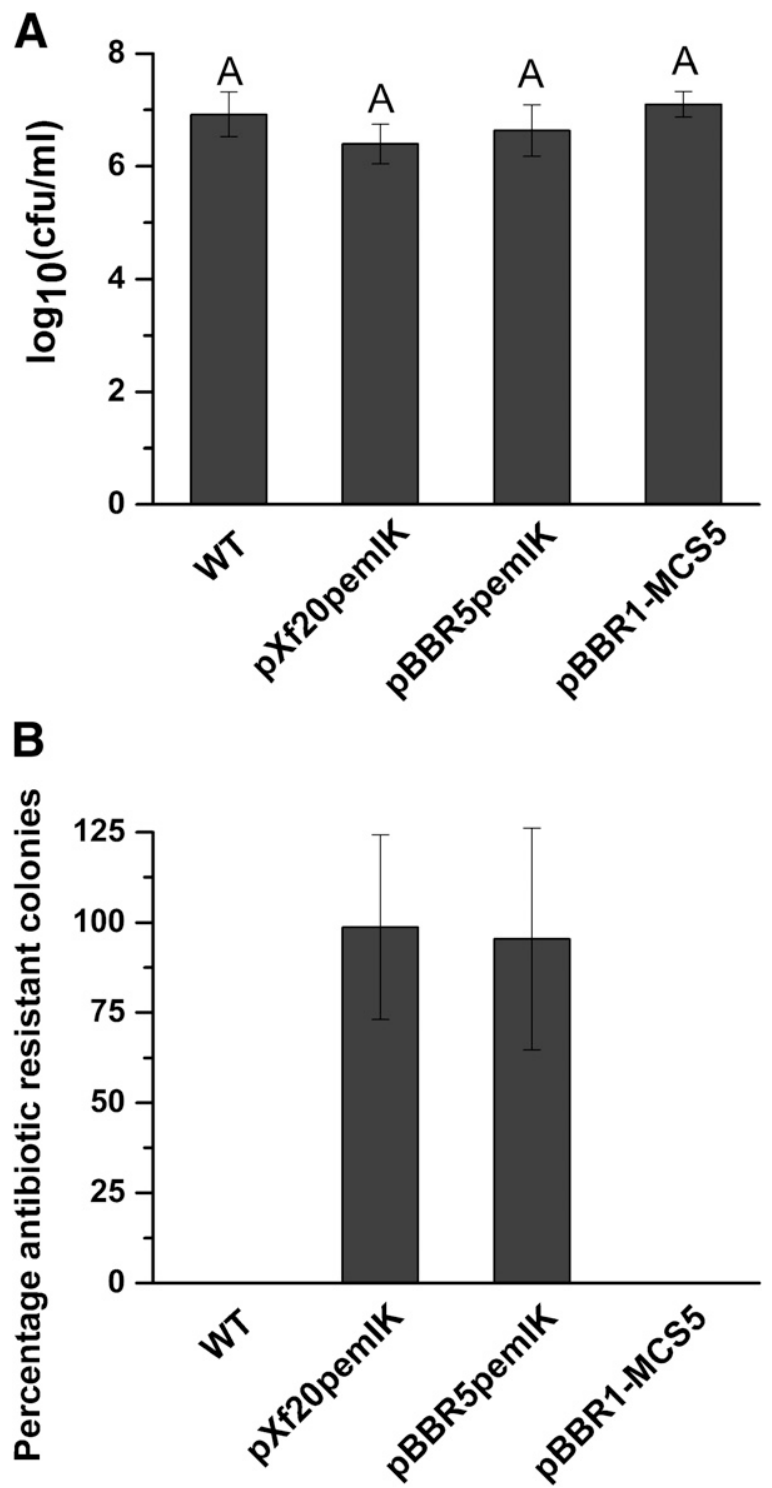

Fig. 5. Stability of pXf20pemIK and pBBR5pemIK in planta. Bacterial populations were isolated from petioles of symptomatic leaves after 14 weeks postinoculation. Petiole samples were surface sterilized and ground in $1 \times$ phosphate-buffered saline. Serial dilutions were plated on PD3 medium with and without antibiotics. CFU were quantified and normalized to original tissue weight. A, Total CFU of strains carrying different plasmids were compared with CFU from wild-type (WT) inoculated plants to determine whether plasmids had any effect on bacterial fitness in the plant. B, Percentage of cells still retaining the plasmids were determined by antibiotic-resistant CFU divided by total CFU. Bars represent the mean of 10 samples taken from different plants and plated in triplicate. Error bars indicate standard deviations. Bars with the same letters are not significantly different based on analysis of variance $(\alpha=0.05)$. with wild-type gene expression. This suggests that repression through native promoter sequences is able to partially compensate for increased gene dosage caused by expression on a multicopy plasmid. In instances where overexpression of exogenous genes is desirable, this could be a benefit; however, in specific cases where it is essential to have very tightly regulated gene expression at the transcriptional level, the vectors described here may need further modification to adjust promoter strength.

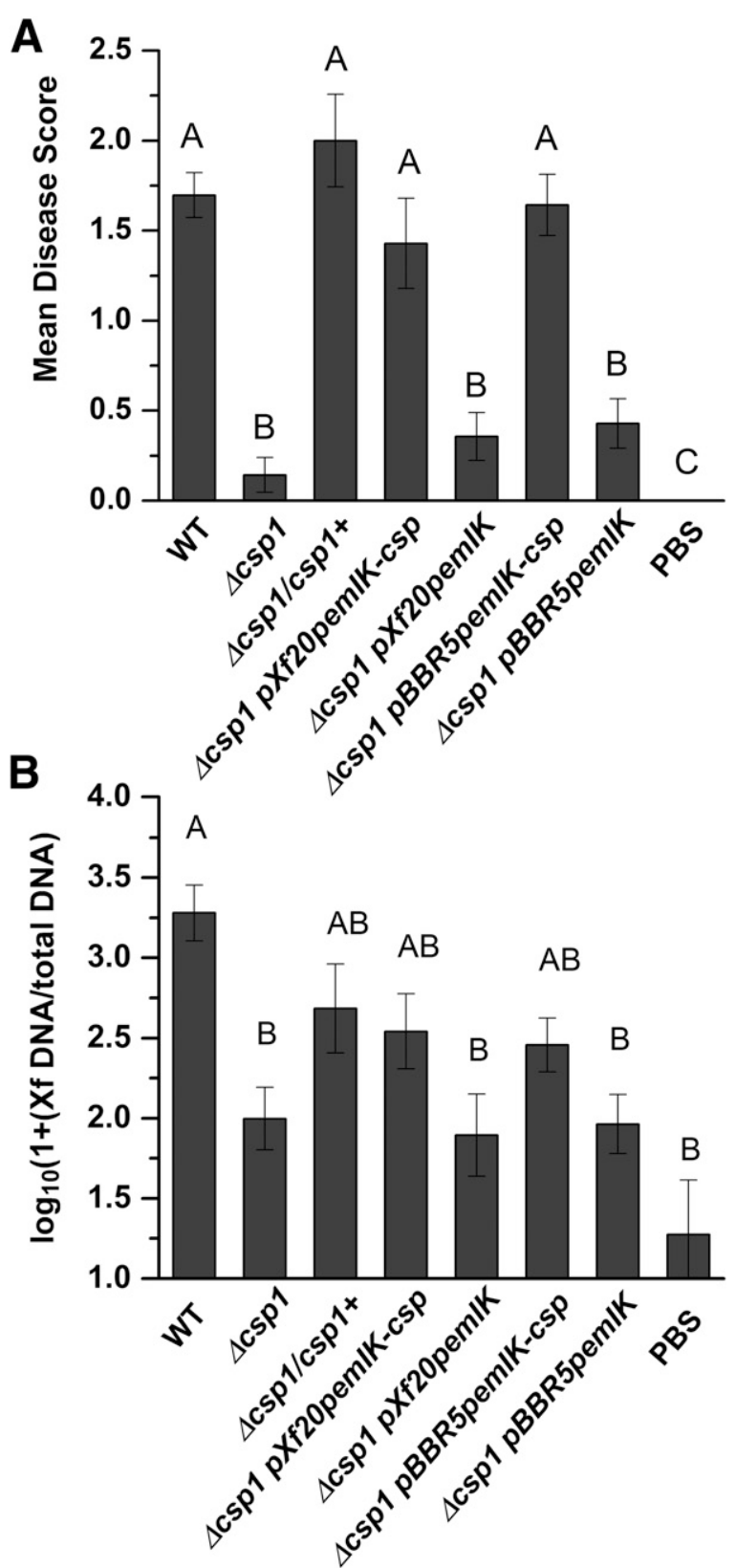

Fig. 6. Complementation of $\Delta c s p 1$ mutant in planta using plasmid vectors. Susceptible grapevines (Vitis vinifera Chardonnay) were needle inoculated with wild-type Stag's Leap (WT), a cspl deletion mutant $(\Delta c s p 1)$, or complemented strains $\Delta c s p / c s p^{+}, \Delta \operatorname{csp} 1 \mathrm{pXf} 20$ pemIK-cspl, and $\Delta \operatorname{csp} 1 \mathrm{pBBR} 5$ pemIKcspl in addition to empty-vector control strains $\Delta c s p 1$ pXf20pemIK and $\Delta c s p 1$ pBBR5pemIK. Plants inoculated with phosphate-buffered saline served as negative controls. After 12 weeks postinoculation, A, symptoms were quantified using a 0-to-5 rating scale (Roper et al. 2007) and B, bacterial quantity was determined by quantitative polymerase chain reaction based on a standard curve of WT genomic DNA and normalized to total DNA concentration. Quantity of Xylella fastidiosa DNA was determined. Bars represent means ( \pm standard error); means with different letters are significantly different based on analysis of variance followed by a Tukey-Kramer multiple comparison test $(\alpha=0.05)$. 


\section{ACKNOWLEDGMENTS}

We thank K. Zhang for technical support and M. S. Sisterson for statistical analysis. Funding for this work was from USDA-ARS appropriated project 2034-22000-010-00D. Mention of trade names or commercial products in this publication is solely for the purpose of providing specific information and does not constitute endorsement by the U.S. Department of Agriculture. USDA is an equal opportunity provider and employer.

\section{LITERATURE CITED}

Antoine, R., and Locht, C. 1992. Isolation and molecular characterization of a novel broad-host-range plasmid from Bordetella bronchiseptica with sequence similarities to plasmids from Gram-positive organisms. Mol. Microbiol. 6:1785-1799.

Blower, T. R., Salmond, G. P. C., and Luisi, B. F. 2011. Balancing at survival's edge: The structure and adaptive benefits of prokaryotic toxin-antitoxin partners. Curr. Opin. Struct. Biol. 21:109-118.

Burbank, L. P., and Stenger, D. 2016. A temperature-independent cold-shock protein homolog acts as a virulence factor in Xylella fastidiosa. Mol. PlantMicrobe Interact. 29:335-344

Chen, J., Groves, R., Civerolo, E. L., Freeman, M., and Zheng, Y. 2005. Two Xylella fastidiosa genotypes associated with almond leaf scorch disease on the same location in California. Phytopathology 95:708-714.

Clifford, J. C., Rapicavoli, J. N., and Roper, M. C. 2013. A rhamnose-rich O-antigen mediates adhesion, virulence, and host colonization for the xylem-limited phytopathogen Xylella fastidiosa. Mol. Plant-Microbe Interact. 26:676-685.

Cuppels, D. A. 1986. Generation and characterization of Tn 5 insertion mutations in Pseudomonas syringae pv. tomato. Appl. Environ. Microbiol. 51: 323-327.

Daniels, M., Barber, C., Turner, P., Cleary, W., and Sawczyc, M. 1984. Isolation of mutants of Xanthomonas campestris pv. campestris showing altered pathogenicity. Microbiology 130:2447-2455.

Davis, M., French, W., and Schaad, N. 1981. Axenic culture of the bacteria associated with phony disease of peach and plum leaf scald. Curr. Microbiol. 6:309-314.

de Mello Varani, A., Souza, R. C., Nakaya, H. I., de Lima, W. C., Paula de Almeida, L. G., Kitajima, E. W., Chen, J., Civerolo, E., Vasconcelos, A. T. R., and Van Sluys, M.-A. 2008. Origins of the Xylella fastidiosa prophage-like regions and their impact in genome differentiation. PLoS One 3:e4059.

Elzer, P. H., Kovach, M. E., Phillips, R. W., Robertson, G. T., Peterson, K. M., and Roop Ii, R. M. 1995. In vivo and in vitro stability of the broadhost-range cloning vector pBBR1MCS in six Brucella species. Plasmid 33:51-57.

Guilhabert, M. R., Hoffman, L. M., Mills, D. A., and Kirkpatrick, B. C. 2001. Transposon mutagenesis of Xylella fastidiosa by electroporation of Tn5 synaptic complexes. Mol. Plant-Microbe Interact. 14:701-706.

Guilhabert, M. R., and Kirkpatrick, B. C. 2003. Transformation of Xylella fastidiosa with broad host range RSF1010 derivative plasmids. Mol. Plant Pathol. 4:279-285.

Guilhabert, M. R., and Kirkpatrick, B. C. 2005. Identification of Xylella fastidiosa antivirulence genes: Hemagglutinin adhesins contribute to $X$. fastidiosa biofilm maturation and colonization and attenuate virulence. Mol. Plant-Microbe Interact. 18:856-868.

Heckman, K. L., and Pease, L. R. 2007. Gene splicing and mutagenesis by PCR-driven overlap extension. Nat. Protoc. 2:924-932.

Hill, B. L., and Purcell, A. H. 1995. Multiplication and movement of Xylella fastidiosa within grapevine and four other plants. Phytopathology 85: 1368-1372.

Hopkins, D. L. 1989. Xylella Fastidiosa: Xylem-limited bacterial pathogen of plants. Annu. Rev. Phytopathol. 27:271-290.

Hopkins, D. L., and Purcell, A. H. 2002. Xylella fastidiosa: Cause of Pierce's disease of grapevine and other emergent diseases. Plant Dis. 86:1056-1066.

Jahn, C. E., Charkowski, A. O., and Willis, D. K. 2008. Evaluation of isolation methods and RNA integrity for bacterial RNA quantification. J. Microbiol. Methods 75:318-324.

Kovach, M. E., Elzer, P. H., Hill, D. S., Robertson, G. T., Farris, M. A., Roop, R. M., and Peterson, K. M. 1995. Four new derivatives of the broad host range cloning vector pBBR1-MCS carrying different antibiotic-resistance cassettes. Gene 166:175-176.

Krivanek, A. F., Stevenson, J. F., and Walker, M. A. 2005. Development and comparison of symptom indices for quantifying grapevine resistance to Pierce's disease. Phytopathology 95:36-43.

Ledbetter, C. A., and Rogers, E. E. 2009. Differential susceptibility of Prunus germplasm (Subgenus Amygdalus) to a California isolate of Xylella fastidiosa. HortScience 44:1928-1931.
Lee, C. L., Ow, D. S. W., and Oh, S. K. W. 2006. Quantitative real-time polymerase chain reaction for determination of plasmid copy number in bacteria. J. Microbiol. Methods 65:258-267.

Lee, M. W., Rogers, E. E., and Stenger, D. C. 2010. Functional characterization of replication and stability factors of an incompatibility group P-1 plasmid from Xylella fastidiosa. Appl. Environ. Microbiol. 76:7734-7740.

Lee, M. W., Rogers, E. E., and Stenger, D. C. 2012. Xylella fastidiosa Plasmidencoded PemK toxin is an endoribonuclease. Phytopathology 102:32-40.

Lee, M. W., Tan, C. C., Rogers, E. E., and Stenger, D. C. 2014. Toxin-antitoxin systems mqsR/ygiT and dinJ/relE of Xylella fastidiosa. Physiol. Mol. Plant Pathol. 87:59-68.

Matsumoto, A., and Igo, M. M. 2010. Species-specific type II restrictionmodification system of Xylella fastidiosa Temecula1. Appl. Environ. Microbiol. 76:4092-4095.

Matsumoto, A., Huston, S. L., Killiny, N., and Igo, M. M. 2012. XatA, an AT-1 autotransporter important for the virulence of Xylella fastidiosa Temecula1. MicrobiologyOpen 1:33-45.

Matsumoto, A., Young, G. M., and Igo, M. M. 2009. Chromosome-based genetic complementation system for Xylella fastidiosa. Appl. Environ. Microbiol. 75:1679-1687.

Minsavage, G. V., Thomson, C. M., Hopkins, D. L., Leite, R. M. V. B. C., and Stall, R. E. 1994. Development of a polymerase chain reaction protocol for detection of Xylella fastidiosa in plant tissue. Phytopathology 84:456-461.

Mohammadi, M., Burbank, L., and Roper, M. C. 2012. Pantoea stewartii subsp. stewartii produces an endoglucanase that is required for full virulence in sweet corn. Mol. Plant-Microbe Interact. 25:463-470.

Purcell, A. H., Saunders, S. R., Hendson, M., Grebus, M. E., and Henry, M. J. 1999. Causal role of Xylella fastidiosa in oleander leaf scorch disease. Phytopathology 89:53-58.

Reddy, J. D., Reddy, S. L., Hopkins, D. L., and Gabriel, D. W. 2007. TolC is required for pathogenicity of Xylella fastidiosa in Vitis vinifera grapevines. Mol. Plant-Microbe Interact. 20:403-410.

Rogers, E. E., and Stenger, D. C. 2012. A conjugative $38 \mathrm{kB}$ plasmid is present in multiple subspecies of Xylella fastidiosa. PLoS One 7:e52131.

Roper, M. C., Greve, L. C., Warren, J. G., Labavitch, J. M., and Kirkpatrick, B. C. 2007. Xylella fastidiosa requires polygalacturonase for colonization and pathogenicity in Vitis vinifera grapevines. Mol. Plant-Microbe Interact. 20:411-419.

Stenger, D. C., and Lee, M. W. 2011. Phylogeny of replication initiator protein TrfA reveals a highly divergent clade of incompatibility group P1 plasmids. Appl. Environ. Microbiol. 77:2522-2526.

Stenger, D. C., Lee, M. W., Rogers, E. E., and Chen, J. 2010. Plasmids of Xylella fastidiosa mulberry-infecting strains share extensive sequence identity and gene complement with pVEIS01 from the earthworm symbiont Verminephrobacter eiseniae. Physiol. Mol. Plant Pathol. 74:238-245.

Syed, M. A., and Lévesque, C. M. 2012. Chromosomal bacterial type II toxin-antitoxin systems. Can. J. Microbiol. 58:553-562.

Tsuchimoto, S., Nishimura, Y., and Ohtsubo, E. 1992. The stable maintenance system pem of plasmid R100: Degradation of PemI protein may allow PemK protein to inhibit cell growth. J. Bacteriol. 174:4205-4211.

Tsuchimoto, S., Ohtsubo, H., and Ohtsubo, E. 1988. Two genes, pemK and pemI, responsible for stable maintenance of resistance plasmid R100. J. Bacteriol. 170:1461-1466.

Unterholzner, S. J., Poppenberger, B., and Rozhon, W. 2013. Toxin-antitoxin systems: Biology, identification, and application. Mob. Genet. Elements 3:e26219.

Van Sluys, M. A., de Oliveira, M. C., Monteiro-Vitorello, C. B., Miyaki, C. Y., Furlan, L. R., Camargo, L. E. A., da Silva, A. C. R., Moon, D. H., Takita, M. A., Lemos, E. G. M., Machado, M. A., Ferro, M. I. T., da Silva, F. R., Goldman, M. H. S., Goldman, G. H., Lemos, M. V. F., El-Dorry, H., Tsai, S. M., Carrer, H., Carraro, D. M., de Oliveira, R. C., Nunes, L. R., Siqueira, W. J., Coutinho, L. L., Kimura, E. T., Ferro, E. S., Harakava, R., Kuramae, E. E., Marino, C. L., Giglioti, E., Abreu, I. L., Alves, L. M. C., do Amaral, A. M., Baia, G. S., Blanco, S. R., Brito, M. S., Cannavan, F. S., Celestino, A. V., da Cunha, A. F., Fenille, R. C., Ferro, J. A., Formighieri, E. F., Kishi, L. T., Leoni, S. G., Oliveira, A. R., Rosa, V. E., Jr., Sassaki, F. T., Sena, J. A. D., de Souza, A. A., Truffi, D., Tsukumo, F., Yanai, G. M., Zaros, L. G., Civerolo, E. L., Simpson, A. J. G., Almeida, N. F., Jr., Setubal, J. C., and Kitajima, J. P. 2003. Comparative analyses of the complete genome sequences of Pierce's disease and citrus variegated chlorosis strains of Xylella fastidiosa. J. Bacteriol. 185:1018-1026.

Walhout, A. J. M., Temple, G. F., Brasch, M. A., Hartley, J. L., Lorson, M. A., van den Heuvel, S., and Vidal, M. 2000. GATEWAY recombinational cloning: Application to the cloning of large numbers of open reading frames or ORFeomes. Methods Enzymol. 328:575-592, IN7.

Zaini, P. A., Fogaça, A. C., Lupo, F. G. N., Nakaya, H. I., Vêncio, R. Z. N., and da Silva, A. M. 2008. The iron stimulon of Xylella fastidiosa includes genes for type IV pilus and colicin V-like bacteriocins. J. Bacteriol. 190:2368-2378.

Zhang, J., Zhang, Y., Zhu, L., Suzuki, M., and Inouye, M. 2004. Interference of mRNA function by sequence-specific endoribonuclease PemK. J. Biol. Chem. 279:20678-20684. 